Check for updates

Cite this: RSC Adv., 2018, 8, 29890

\title{
Tuning the porosity and surface characteristics of nanoporous titania using non-ionic surfactant reverse micelles $\uparrow$
}

\author{
Polyxeni Paschalidou and Charis R. Theocharis (iD *
}

\begin{abstract}
Nanoporous titania was prepared from non-ionic surfactant reverse micelles (e.g. Triton-X) and the effects of the chain length of the surfactants and calcination temperature of the precursor gels on the surface properties of the product (mesoporous titania) were investigated. The studies included sample characterization of the precursor gels from the titania samples characterized by UV-Vis, ATR-FTIR, XRD, TGA/DSC and the titania samples by $\mathrm{N}_{2}$-adsorption BET, XRD, FT-IR, UV-Vis diffuse reflectance and SEM measurements after calcination at $400{ }^{\circ} \mathrm{C}, 500{ }^{\circ} \mathrm{C}, 600{ }^{\circ} \mathrm{C}, 700{ }^{\circ} \mathrm{C}$ and $800{ }^{\circ} \mathrm{C}$. According to the experimental results, generally increasing the length of the polar tail of Triton- $\mathrm{X}$ results in an increased specific surface area and volume, and an average pore diameter of the solids. Moreover, increasing the length of the polar tail is associated with a smaller crystallite size and higher thermal stability of the materials. Finally, a nucleation mechanism of the titania particles within the aqueous centre of the reversed micelles is proposed.
\end{abstract}

Received 27th June 2018

Accepted 10th August 2018

DOI: $10.1039 / \mathrm{c} 8 \mathrm{ra05495a}$

rsc.li/rsc-advances

the formation of titania in micellar compartments favours the

\section{Introduction}

Titania $\left(\mathrm{TiO}_{2}\right)$ is widely used in many industrial applications (for example, heterogeneous catalysis, photocatalysis, adsorption, pigments) because of its electronic properties, stability and availability. ${ }^{1-4}$ Moreover, titania is expected to play a key role in a number of high-impact fields, such as energy production and clean technologies. ${ }^{5}$ In this context, the preparation of mesoporous $\mathrm{TiO}_{2}$ materials with a high surface area and controlled pore size is of particular interest. ${ }^{6}$

There has been a large number of papers published describing several different synthetic methods for the synthesis of mesoporous $\mathrm{TiO}_{2}$ materials. ${ }^{7}$ These methods include hydrothermal processes, ${ }^{8-10}$ pyrolysis, ${ }^{11}$ thermal decomposition, ${ }^{12}$ alkaline precipitation, ${ }^{13,14}$ combustion, ${ }^{15}$ mechanochemical and electrochemical methods, ${ }^{16,17}$ sol-gel methods, ${ }^{18}$ gas-phase condensation, ${ }^{19}$ microwave and ultrasound techniques. ${ }^{20,21}$

Precipitation and sol-gel methods have been applied also in combination with colloidal systems (e.g. emulsions and microemulsions) or surfactants and polymers to better control the surface properties and purity of the prepared solids. ${ }^{22-25}$ The variety of emulsions, polymers and surfactants available allows the design of a large number of preparation pathways and the production of $\mathrm{TiO}_{2}$ materials with controlled textural and surface properties ${ }^{6,722,26}$. In addition, the use of surfactants and

Porous Solids Group, Department of Chemistry, University of Cyprus, P. O. Box 20537, 1678, Nicosia, Cyprus. E-mail: charis@ucy.ac.cy

$\dagger$ Electronic supplementary information (ESI) available: Textural properties of titania prepared in the presence of Triton-X. See DOI: 10.1039/c8ra05495a stabilization of nanosized $\mathrm{TiO}_{2}$ particles. ${ }^{23-25,27,28}$ Despite the fact that non-ionic surfactants have several advantages (e.g. weak repulsion interactions, easy removal) the number of studies related to titania preparation by means of Triton- $X$ is limited..$^{23,28-31}$ Triton-X has been used basically in the preparation of titania by pressurized fluid extraction and supercritical drying methods. .,6,7,32-35 $^{-1}$

Several studies have been published in which reverse micelles have been used in the synthesis of nanoporous materials. In this paper, we present the first systematic study of the synthesis of porous titanium dioxide with the use of electrically neutral amphiphilic molecules of the so-called Triton-X series forming reverse micelles. This allowed us to study the effect of the alkyl chain length on the synthesis of the inorganic product. We also studied the effects of the synthesis and post-synthesis conditions on the surface properties of the product. We were able to study the nucleation of titania particles within the aqueous core of the inverse micelles. We also studied the reaction of water in the core of the micelles and the alkoxide titanium precursor in the non-aqueous exterior of the micelles, requiring the migration of the alkoxide into the core, and through the exterior of the micelle.

Further, we studied the effect of the calcination temperature of the precursor gels on the surface properties of the titania solids produced. Moreover, the effect of cyclohexane treatment prior to calcination on the surface characteristics of titania was studied. Finally, a nucleation mechanism of the $\mathrm{TiO}_{2}$ particles within the aqueous centre of the reversed micelles is proposed. 


\section{Experimental}

$\mathrm{TiO}_{2}$ solid samples were prepared using $\mathrm{Ti}\left(\mathrm{O}^{\mathrm{i}} \mathrm{Pr}\right)_{4}$ as the precursor $^{36,37}$ and Triton-X to form the non-ionic reverse micelle microemulsions. Specifically, three different mixtures of reversed micelles were prepared by mixing separately Triton X100 (extra pure, Fisher Chemical), Triton X-114 (extra pure, Sigma-Aldrich) and Triton X-45 (extra pure, Sigma-Aldrich) and cyclohexane (99.98\%, Fisher Chemical) at a concentration of $1.2 \mathrm{~mol} \mathrm{~kg}^{-1}$. Next, deionized water (Merck Millipore) was added at a molar ratio of 0.8 . The mixture was stirred under a $\mathrm{N}_{2}$-atmosphere for $1 \mathrm{~h}$ to form the reversed micelles with the aqueous compartment in their centre. Then, $\mathrm{Ti}\left(\mathrm{O}^{\mathrm{i}} \mathrm{Pr}\right)_{4}$ was added at a molar ratio of one $\left(\left[\mathrm{Ti}\left(\mathrm{O}^{\mathrm{i}} \mathrm{Pr}\right)_{4}\right] /\left[\mathrm{H}_{2} \mathrm{O}\right]=1\right)$ and the mixture was left for $48 \mathrm{~h}$ under ambient conditions to form the corresponding gels. Prior to calcination, the gels were stirred for $16 \mathrm{~h}$ with an excess of cyclohexane to remove the organic phase from the inorganic residual $\left(\mathrm{TiO}_{2}\right.$ solids). Finally, aliquots of the $\mathrm{TiO}_{2}$ residuals were calcined at $400{ }^{\circ} \mathrm{C}, 500{ }^{\circ} \mathrm{C}, 600{ }^{\circ} \mathrm{C}, 700{ }^{\circ} \mathrm{C}$ and $800{ }^{\circ} \mathrm{C}$ for $2 \mathrm{~h}$.

The gels and the powders obtained upon calcination were characterized using a variety of techniques, such as UV-Vis absorption spectroscopy (Shimadzu, UV-2401PC), UV-Vis Reflection Spectroscopy (USB2000, Ocean Optics), ATR and FTIR spectroscopy (Shimadzu, FT-8900), X-ray diffraction (Shimadzu, XRD-6000), SEM (Vega TS5136LS-Tescan), TGA (Shimadzu TGA-50) and DSC (TA Universal Analysis 2010 Quantachrome DSC-Q100 model). Nitrogen adsorption/ desorption isotherms were obtained using an ASAP-2010 Micromeritics apparatus and the specific surface areas were calculated from the adsorption data using the BrunauerEmmett-Teller method, whilst the pore size distributions were estimated from the isotherms using both the DFT methods (a program supplied with the instrument) employing an inkbottle-shaped pore model and the BJH method.

\section{Results and discussion}

\section{Characterisation of the $\mathrm{TiO}_{2}$-Triton-X gels}

At the beginning of the reaction, the two reagents are on the opposite sides of the micelles, with water in the core, and titanium isopropoxide dissolved in the solvent outside. The isopropoxide can diffuse through the chains of the surfactant towards the aqueous centre. There, it can either insert itself into the micelle with the $\mathrm{O}^{-} \cdots \mathrm{Ti}^{4+}$ moiety towards the core, or can penetrate as a whole inside, either way resulting in exposure to water and subsequent reaction to form titania. As more titanium ions are introduced and hydrolyzed, small crystallites of the titania structure are formed eventually, disrupting the mechanical integrity of the micelle and causing it to disintegrate. This allows crystallites to assemble, grow in size and precipitate into a well-defined solid. Furthermore, the use of an organometallic precursor for the oxide enables better control of the hydrolysis and precipitation processes. The micelles provide a means of structure-directing action. Furthermore, there is no fast and uncontrolled precipitation taking place.

The neutral surfactant Triton-X was used because the lack of charges meant that it was involved only in weak dispersive forces, allowing a higher extent of reactions to give titania. This also leads to the synthesis of more thermally stable solids, where after the precipitation of titania, the organic residues could be easily removed thermally. Finally, there is a scarcity of papers discussing the effect of different chain lengths.

A small amount of water was used in the synthesis, as this would give rise to a smaller micelle diameter.

A longer tail length may indeed result in a larger overall diameter, but would not influence the size of the aqueous core. On the other hand, a longer chain length will result in higher disorder of the chains and will interfere with the diffusion of the isopropoxide moieties towards the core, in order for hydrolysis to take place.

Water in the micelle core consists of free water molecules that are available for reaction with the titanium ions. There may be water molecules that are hydrogen-bonded to both the hydrophilic end of the surfactant molecules, as well as the titanium ions. These will stabilize the micelles, but would not interfere in the precipitation reaction. The only water present is that added during the micelle forming step.

Fig. 1 shows images of the $\mathrm{TiO}_{2}$-Triton-X gels corresponding to the three different types of Triton-X studied (Triton X-100, Triton X-114 and Triton X-45). The gels are clear, indicating the successful preparation of the $\mathrm{TiO}_{2}$ nanoparticles within the cavities of the reverse micelles. ${ }^{23}$ In contrast to the two other gels, which are almost colourless, the gel corresponding to Triton X-114 has an intense yellow colour, most probably related to the size of the formed $\mathrm{TiO}_{2}$ nanoparticles.

The XRD diffractograms obtained for the three different gels are shown in Fig. 2A and indicate the formation of nanosized
(A)

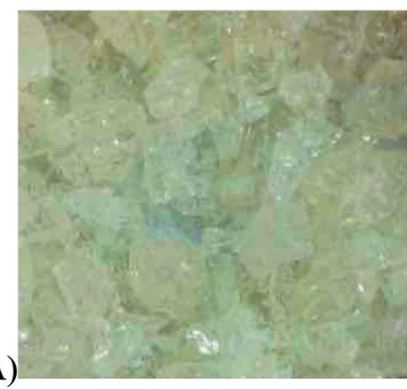

(B)

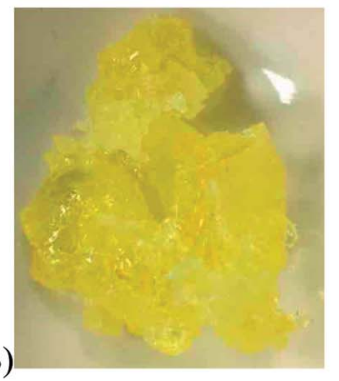

(C)

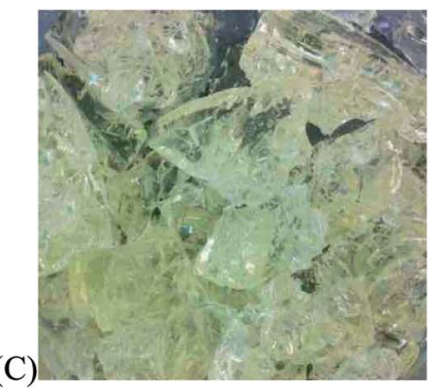

Fig. 1 Images of the three different $\mathrm{TiO}_{2}$-Triton-X gels, corresponding to (A) Triton X-100, (B) Triton X-114 and (C) Triton X-45. 
(A)
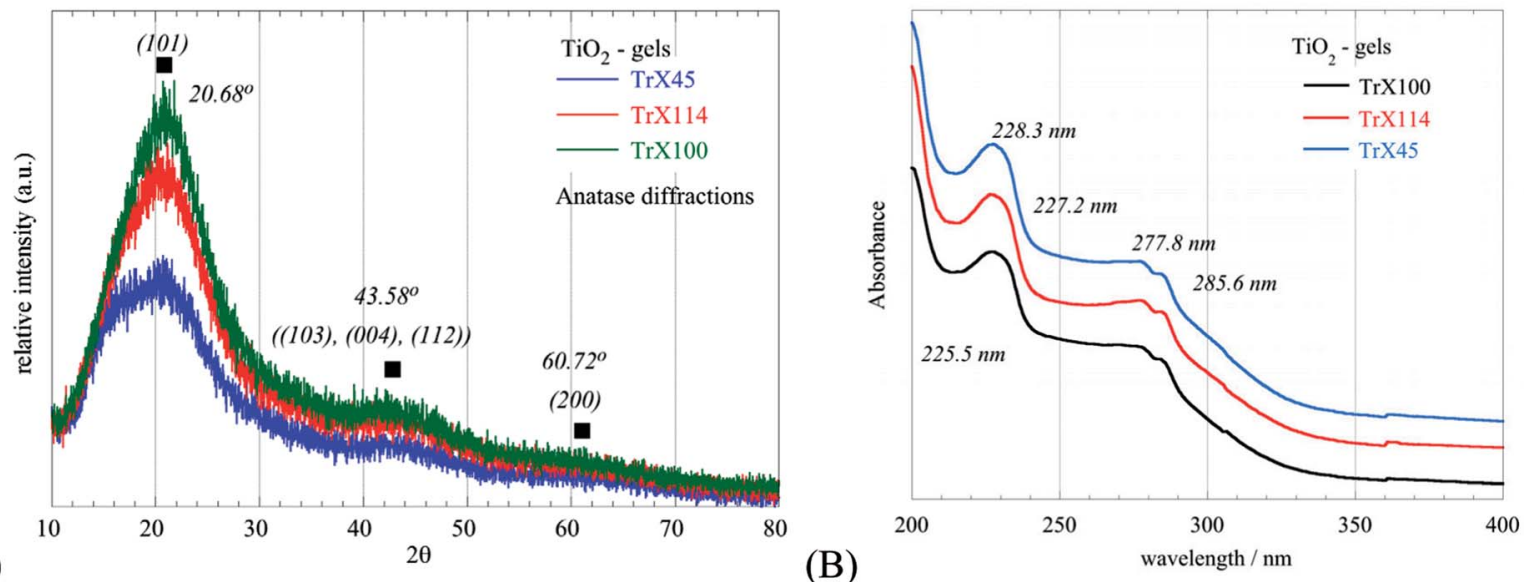

Fig. 2 XRD diffractograms (A) and UV-Vis spectra (B) of the three different $\mathrm{TiO}_{2}$-Triton-X gels.

Table 1 XRD and UV-Vis data corresponding to the three different $\mathrm{TiO}_{2}$-Triton-X gels

\begin{tabular}{llllllll}
\hline Gel sample & $2 \theta_{\text {Bragg }}\left({ }^{\circ}\right)$ & Level & $d_{\text {Bragg }}(\AA)$ & FWHM $\left(^{\circ}\right)$ & $L_{\text {XRD }}(\mathrm{nm})$ & Peak TiO $_{2}(\mathrm{~nm})$ & Band gap TiO $_{2}(\mathrm{eV})$ \\
\hline $\mathrm{TiO}_{2}-\operatorname{TrX}-100$ & 25.19 & $(101)$ & 3.5324 & 1.71 & 4.99 & 225.5 & 5.5 \\
$\mathrm{TiO}_{2}-\operatorname{TrX}-114$ & 25.57 & $(101)$ & 3.4809 & 1.62 & 5.26 & 227.2 & 5.46 \\
$\mathrm{TiO}_{2}-\operatorname{TrX}-145$ & 26.05 & $(101)$ & 3.4179 & 0.81 & 10.52 & 228.3 & 5.43
\end{tabular}

$\mathrm{TiO}_{2}$ particles. The broad peaks at $2 \theta$ values of $20.68^{\circ}, 43.58^{\circ}$ and $60.72^{\circ}$, corresponding to the (101), ((103), (004), (112)) and (200) reflections, respectively, indicate the formation of anatase, which is the metastable form of titania. ${ }^{38,39}$ Moreover, based on the Debye-Scherrer equation the crystal size ( $\left.L_{\mathrm{XRD}}\right)$ was evaluated $^{\mathbf{4 0}}$ and the corresponding data are summarized in Table 1. From these data, it is clear that smaller surfactant tail lengths are associated with smaller $L_{\mathrm{XRD}}$ values and hence smaller $\mathrm{TiO}_{2}$ crystallites. This was corroborated also from the energy band gap values (Table 1) evaluated from the UV-Vis spectra of the $\mathrm{TiO}_{2}$-Triton-X gels shown in Fig. 2B. Specifically, with an increasing length of the surfactant tail, the UV peaks at $230 \mathrm{~nm}$ are shifted to lower wavelengths, associated with an increasing energy gap and decreasing crystallite size. ${ }^{\mathbf{4 1 , 4 2}}$ The UV peaks around $278 \mathrm{~nm}$ and $285 \mathrm{~nm}$ are similar for all spectra and are ascribed to $p$-substituted phenyl group of the Triton-X surfactants. $^{43}$

\section{Characterisation of the $\mathrm{TiO}_{2}$ solids}

After cyclohexane treatment, aliquots of the $\mathrm{TiO}_{2}$-Triton $\mathrm{X}$ gels were calcined at $400{ }^{\circ} \mathrm{C}$ for $2 \mathrm{~h}$ to remove the organic matrix (TGA/DSC data included in Fig. 1S and Table 1S, ESI $\dagger$ ) and the surface properties of the resulting $\mathrm{TiO}_{2}$ solids were determined by $\mathrm{N}_{2}$ isothermal adsorption/desorption. The corresponding isotherms and pore size distributions are presented in Fig. 3, and the associated data are summarized in Table 2.

In Fig. 3, the isotherms are seen to be of type IV with an $\mathrm{H} 2$ hysteresis loop, which are characteristic for variable diameter pores (ink bottle shaped), indicating the presence of mesopores according to the IUPAC classification. ${ }^{\mathbf{4 4 , 4 5}}$ Moreover, the plateau for $p / p_{\mathrm{o}}>0.7$ indicates the formation of "real" mesopores formed by the aggregation of primary crystallites. From the data in Table 2, it is obvious that generally increasing the length of the surfactant tail results in an increased specific surface area, pore volume and pore diameter, ${ }^{46}$ suggesting that the surface characteristics of the solids can be tailored by choosing a surfactant with an appropriate tail length. The differences in the surface properties between the solid produced after calcination at $400{ }^{\circ} \mathrm{C}$ using the surfactant with the smallest tail (Triton X-45) and the surfactant with the longest tail (Triton X100) were significant. However, although the tail length of Triton X-114 is slightly smaller than the tail length of Triton X100 , the solid produced from the Triton $\mathrm{X}-114 \mathrm{TiO}_{2}$-gel after calcination at $400{ }^{\circ} \mathrm{C}$ presented the highest BET surface area, attributed most probably to specific interactions of the polar tail of Triton X-114 with the inorganic precursors. Regarding the pore size and volume of the $\mathrm{TiO}_{2}$ solid, it is clear from the data presented in Fig. 3 and summarized in Table 2 that both the pore size and volume decreased almost linearly with decreasing tail length, indicating the strong correlation between these parameters. In Table 2, we present the pore diameter data calculated both by the BJH and the DFT methods for comparison. The two methods gave values very close to each other.

Furthermore, the $\mathrm{TiO}_{2}$ solids were characterised by XRD and the corresponding data are presented graphically in Fig. 4 and summarized in Table 3. The diffractrograms corresponding to the three $\mathrm{TiO}_{2}$ solids are similar and show 11 peaks, which can be assigned to anatase, which has a tetragonal crystal structure and is the thermally metastable form of titania. ${ }^{\mathbf{4 0}}$ However, based on the FWHM of the fundamental peak associated with 

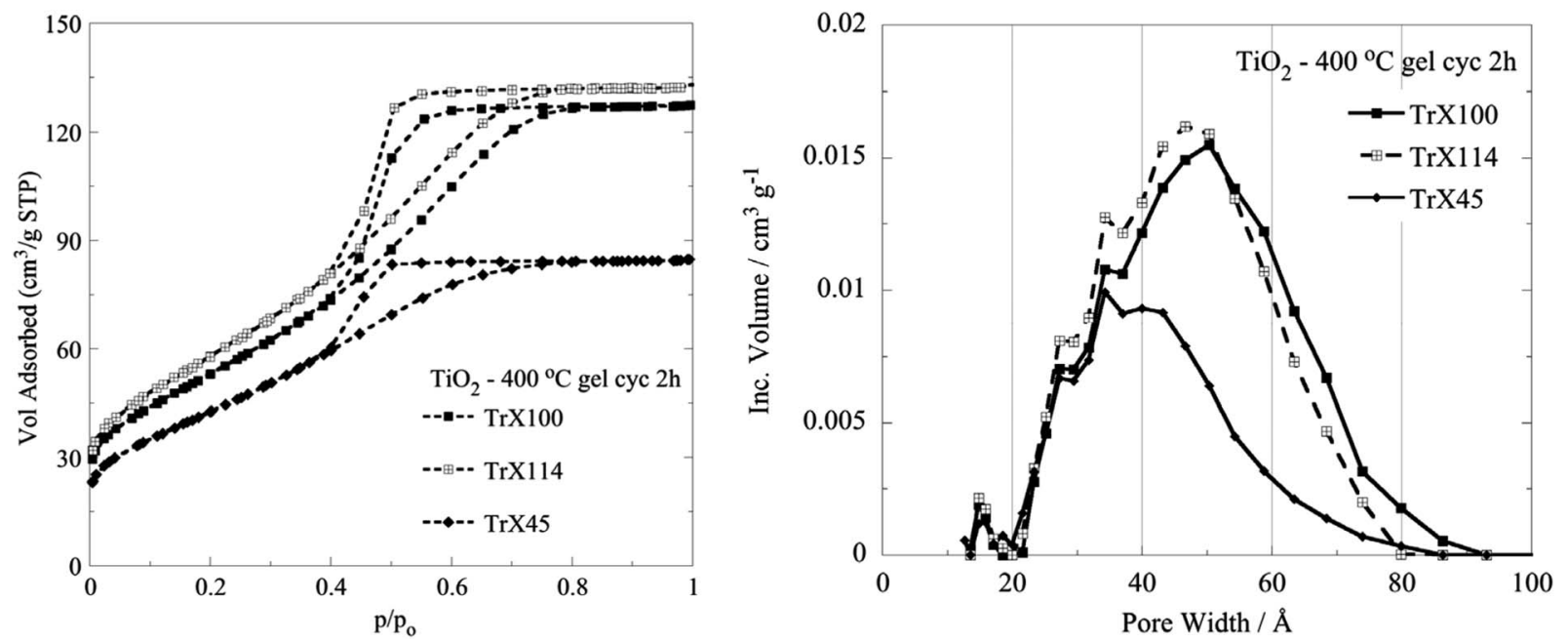

Fig. $3 \mathrm{~N}_{2}$ adsorption/desorption isotherms and DFT pore size distributions of the titania solids obtained after calcination of the corresponding $\mathrm{TiO}_{2}$-Triton $\mathrm{X}$ gels at $400{ }^{\circ} \mathrm{C}$ for $2 \mathrm{~h}$.

Table 2 Characteristic surface data of the titania solids obtained after calcination of the corresponding TiO ${ }_{2}-\mathrm{Triton}_{\mathrm{X}}$ gels at $400{ }^{\circ} \mathrm{C}$ for $2 \mathrm{~h}$

\begin{tabular}{|c|c|c|c|c|c|}
\hline Sample (cyc) & $\begin{array}{l}\text { Tail length } \\
\text { (average EO units) }\end{array}$ & $\operatorname{SpA}_{\mathrm{BET}}\left(\mathrm{m}^{2} \mathrm{~g}^{-1}\right)$ & $V_{\mathrm{Sp}}\left(\mathrm{cm}^{3} \mathrm{~g}^{-1}\right)$ & $d_{\mathrm{BJH}}(\mathrm{nm})$ & $d_{\mathrm{DFT}}(\mathrm{nm})$ \\
\hline $\mathrm{TiO}_{2} \mathrm{TrX}-100400{ }^{\circ} \mathrm{C} 2 \mathrm{~h}$ & $9-10$ & 182.2 & 0.196 & 3.26 & 5.04 \\
\hline $\mathrm{TiO}_{2} \mathrm{TrX}-45400{ }^{\circ} \mathrm{C} 2 \mathrm{~h}$ & $4-5$ & 146.3 & 0.124 & 2.92 & 3.4 \\
\hline
\end{tabular}

the crystal surface (101), the crystallinity of the $\mathrm{TiO}_{2}$ particles formed depends on the Triton X surfactant used. According to the data summarized in Table 3 , the $\mathrm{TiO}_{2}$ particles obtained from Triton X-100 were the most crystalline followed by the solids obtained from Triton X-45 and Triton X-114, which is in agreement with the corresponding surface data.

The FTIR spectra of the three different $\mathrm{TiO}_{2}$ solids obtained after calcination of the related gels are shown in Fig. 5. The peak

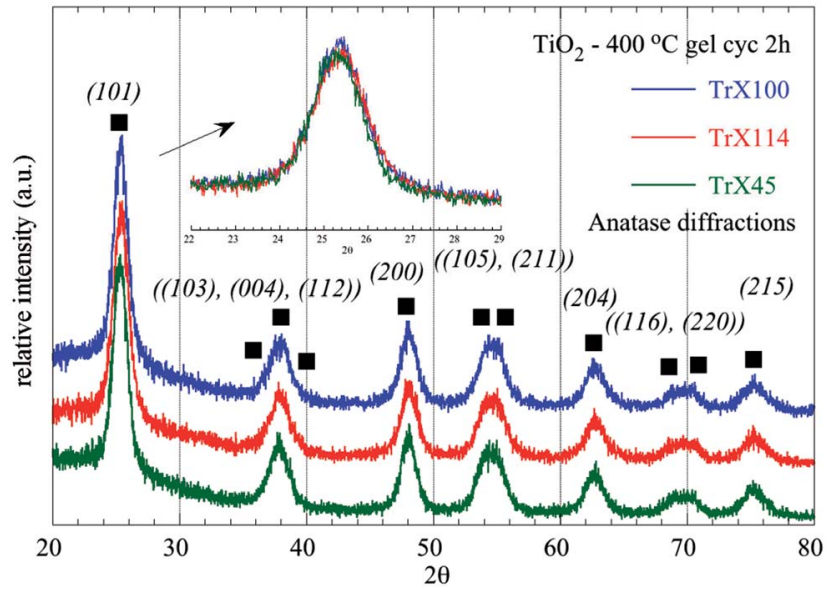

Fig. 4 XRD diffractograms of titania solids obtained after calcination of the three different $\mathrm{TiO}_{2}$ Triton-X gels (Triton X-100, 114 and 45) at $400{ }^{\circ} \mathrm{C}$ for $2 \mathrm{~h}$. at $1626 \mathrm{~cm}^{-1}$ corresponds to adsorbed water, whereas the sharp peak at $1391 \mathrm{~cm}^{-1}$ can be attributed to Ti-OH vibrations. ${ }^{47}$ The broad peak spanning the area $850-400 \mathrm{~cm}^{-1}$ in the FTIR spectra (Fig. 5), which corresponds to vibrations in the $\mathrm{TiO}_{2}$ lattice, is of particular interest. It is noticed that a significant peakbroadening with increasing the surfactant tail length is observed. This effect is due, presumably, to the particle size produced using different Triton $\mathrm{X}$ surfactants and is in agreement with the results obtained from the surface and XRD analyses. Furthermore, DRUV-Vis spectra of the $\mathrm{TiO}_{2}$ solids (Fig. 6) corroborate the effect of the surfactant tail length on the formed particle size. According to Fig. 6, there is a blue-shift of the $\mathrm{TiO}_{2}$ spectra with the decreasing particle size, which is attributed to the fact that smaller particles are associated with a larger energy gap and hence absorption occurs at higher energies. ${ }^{42,48}$

\section{Temperature effect on the surface properties of the $\mathrm{TiO}_{2}$ solids}

The $\mathrm{N}_{2}$ adsorption isotherms obtained for the three different $\mathrm{TiO}_{2}$ solids after calcination at $500{ }^{\circ} \mathrm{C}$ and $600{ }^{\circ} \mathrm{C}$ are presented along with the isotherms obtained after calcination at $400{ }^{\circ} \mathrm{C}$ in Fig. 7.

From the isotherms (Fig. 7), it can be seen that the solids obtained from the calcination of the Triton X-100 gel present the highest thermal stability, followed by the oxide obtained from the calcination of the Triton X-114 and the Triton X-45 gels. It is of particular interest that even after calcination at 
Table 3 XRD diffraction data of $\mathrm{TiO}_{2}$ solids produced after calcination of the three different $\mathrm{TiO}_{2}$ Triton-X gels (Triton X-100, 114 and 45) at $400{ }^{\circ} \mathrm{C}$ for $2 \mathrm{~h}$

\begin{tabular}{|c|c|c|c|c|c|c|}
\hline Sample (cyc) & $\operatorname{SpA}_{\mathrm{BET}}\left(\mathrm{m}^{2} \mathrm{~g}^{-1}\right)$ & $2 \theta_{\text {Bragg }}\left({ }^{\circ}\right)$ & Level & $d_{\text {Bragg }}(\AA)$ & FWHM $\left(^{\circ}\right)$ & $L_{\mathrm{XRD}}(\mathrm{nm})$ \\
\hline $\mathrm{TiO}_{2} \mathrm{TrX}-100400{ }^{\circ} \mathrm{C} 2 \mathrm{~h}$ & 182.2 & 25.37 & $(101)$ & 3.508 & 1.349 & 6.3 \\
\hline $\mathrm{TiO}_{2} \mathrm{TrX}-114400{ }^{\circ} \mathrm{C} 2 \mathrm{~h}$ & 199.3 & 25.39 & $(101)$ & 3.505 & 1.446 & 5.9 \\
\hline
\end{tabular}

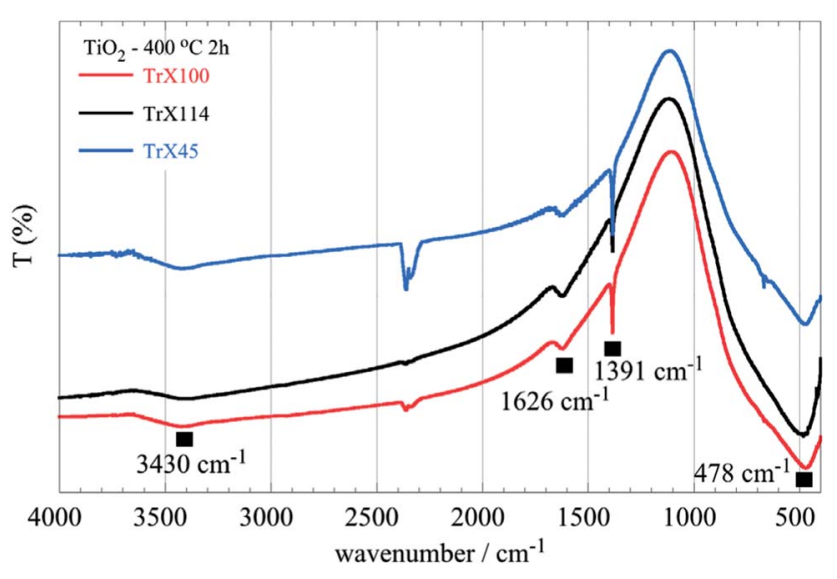

Fig. 5 FTIR spectra of titania solids obtained after calcination of the three different $\mathrm{TiO}_{2}$ Triton-X gels (Triton X-100, 114 and 45 ) at $400{ }^{\circ} \mathrm{C}$ for $2 \mathrm{~h}$.

higher temperatures, the $\mathrm{TiO}_{2}$ solid arising from the Triton X100 gel presents the better surface characteristics (Table 2S, ESI $\dagger$ ), which is due, as already mentioned, to the better interaction of the Triton X-100 polar tail with the inorganic $\mathrm{TiO}_{2}$ precursors.

Moreover, the diffractograms (Fig. 8) show that the transformation of anatase to rutile can be observed for the $\mathrm{TiO}_{2}$ solid

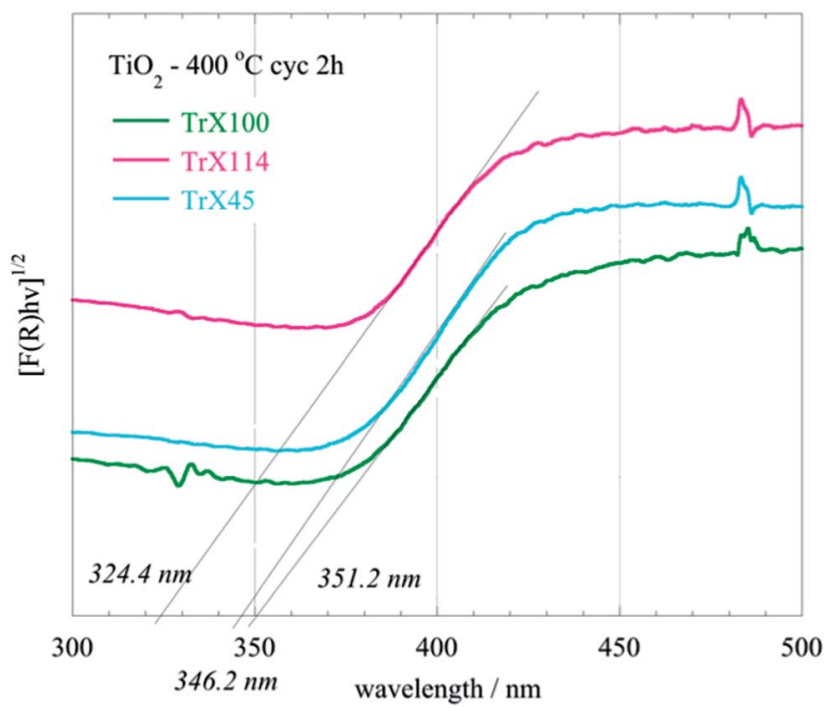

Fig. 6 DRUV-Vis spectra of titania solids obtained after calcination of the three different $\mathrm{TiO}_{2}$ Triton-X gels (Triton X-100, 114 and 45) at $400{ }^{\circ} \mathrm{C}$ for $2 \mathrm{~h}$. obtained from the Triton $\mathrm{X}-100$ gel only at $800{ }^{\circ} \mathrm{C}$ indicating the high thermal stability of the respective sample. In contrast, this transformation for the other $\mathrm{TiO}_{2}$ solids is observed from $700{ }^{\circ} \mathrm{C}$. The peaks corresponding to the rutile phase appear at $2 \theta$ $=27.39^{\circ}, 35.94^{\circ}, 39.13^{\circ}, 41.15^{\circ}, 43.91^{\circ}, 54.2^{\circ}, 56.52^{\circ}, 63.91^{\circ}$, $69.13^{\circ}$ and $69.85^{\circ}$, corresponding to the (110), (101), (200), (111), (210), (211), (220), (002), (301) and (112) crystal planes. ${ }^{49,50}$

The effect of the calcination temperature on the characteristics of the $\mathrm{TiO}_{2}$ solids are supported also by the DRUV-Vis measurements of the samples, as shown in Fig. 9A for the $\mathrm{TiO}_{2}$ solid obtained from the Triton X-45 gel. Generally, with an increased temperature, the particle size increases and the energy gap decreases accordingly (Fig. 9B). However, in the case of the $\mathrm{TiO}_{2}$ solid obtained from the Triton X-45 gel, this does not follow because of the presence of both $\mathrm{TiO}_{2}$ phases (rutile and anatase) in the solid. Hence, the decline in the energy gap due to the increased particle size is compensated by the favoured formation of rutile in the solid at increased calcination temperatures. ${ }^{51}$ These results (XRD \& DRUV-Vis) are in agreement with the presence of a flake morphology in the $\mathrm{TiO}_{2}$ nanoparticles in the SEM micrographs (Fig. 2S, ESI $\dagger$ ), which is related to the rutile structure. ${ }^{52}$

\section{Formation mechanism of $\mathrm{TiO}_{2}$ particles by means of Triton-X reversed micelles}

The reverse micelles studied here are formed when the polar tails of the Triton-X surfactants are oriented around the water droplets and the non-polar heads are oriented towards the organic phase. ${ }^{53}$ The diameter of water droplets formed depends on the chain length of the Triton-X surfactant used ${ }^{28}$ and it is obvious that surfactants with increased tail length form micelles with a higher diameter and inner-space diameter, as schematically shown in Fig. 10.

When the $\mathrm{TiO}_{2}$ precursor compound $\mathrm{Ti}\left(\mathrm{O}^{\mathrm{i}} \mathrm{Pr}\right)_{4}$ is added to the suspension and distributed within the inner-space of the micelles, which is filled with water (water droplets), hydrolysis and condensation of the precursor molecules start, as described by eqn (1) and (2). ${ }^{54}$

$$
\begin{aligned}
& \mathrm{Ti}\left(\mathrm{O}^{\mathrm{i}} \mathrm{Pr}\right)_{4}+4 \mathrm{H}_{2} \mathrm{O} \rightarrow \mathrm{Ti}(\mathrm{OH})_{4}+4^{\mathrm{i}} \mathrm{PrOH} \text { (hydrolysis) } \\
& \mathrm{Ti}(\mathrm{OH})_{4} \rightarrow \mathrm{TiO}_{2} \cdot x \mathrm{H}_{2} \mathrm{O}+(2-x) \mathrm{H}_{2} \mathrm{O} \text { (condensation) }
\end{aligned}
$$

The hydrolysis and condensation rate of the $\mathrm{Ti}\left(\mathrm{O}^{\mathrm{i}} \mathrm{Pr}\right)_{4}$ within the micelles is largely controlled because both reactions can only occur within the aqueous centre of the micelles induced by the interactions of the polar tails with the isopropyl-moieties 

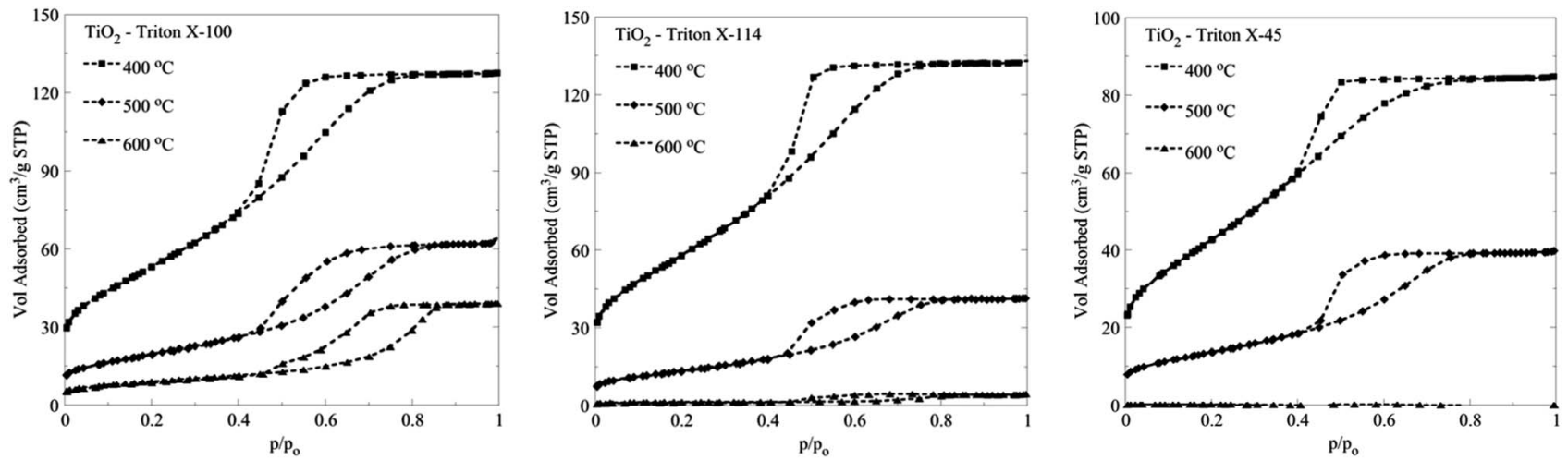

Fig. $7 \mathrm{~N}_{2}$ adsorption isotherms of titania solids obtained after calcination of the three different $\mathrm{TiO}_{2}$ Triton-X gels (Triton X-100, 114 and 45) at $400{ }^{\circ} \mathrm{C}, 500^{\circ} \mathrm{C}$ and $600^{\circ} \mathrm{C}$ for $2 \mathrm{~h}$.
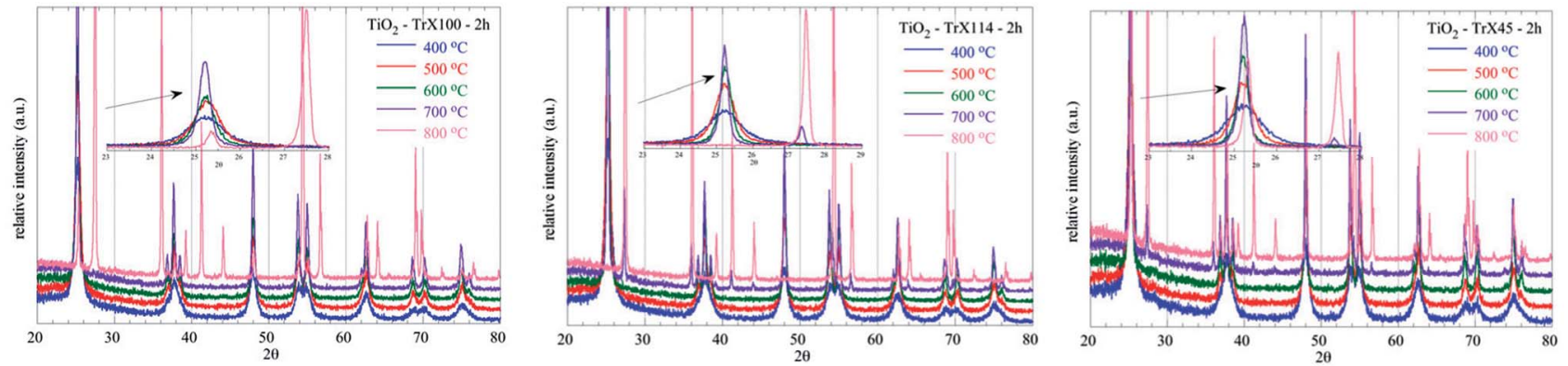

Fig. $8 \mathrm{XRD}$ diffractograms of the $\mathrm{TiO}_{2}$ solids obtained from the three different Triton $\mathrm{X}$ gels and after calcination at various temperatures between $400{ }^{\circ} \mathrm{C}$ and $800^{\circ} \mathrm{C}$.

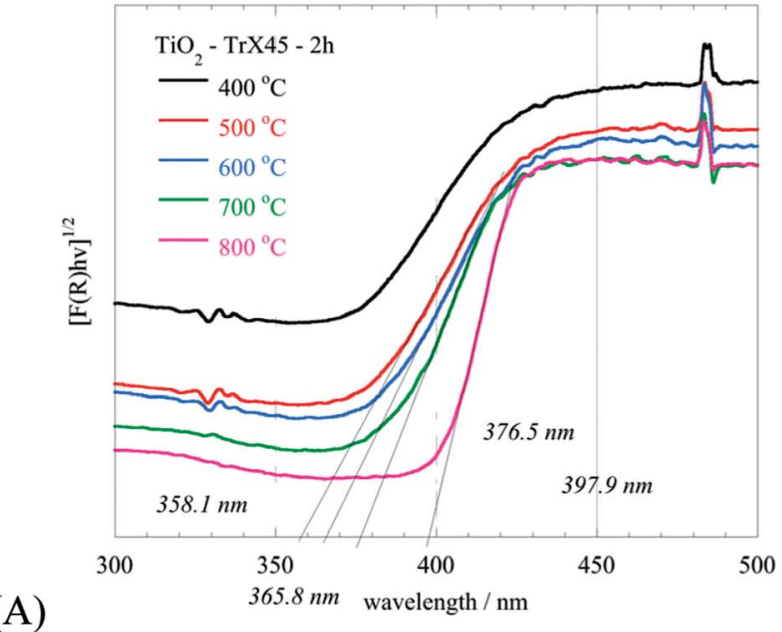

Fig. 9 DRUV-Vis spectra of the $\mathrm{TiO}_{2}$ solid obtained from the Triton $\mathrm{X}-45$ gel after calcination at different temperatures between $400{ }^{\circ} \mathrm{C}$ and $800{ }^{\circ} \mathrm{C}$ (A). Comparative graph of the energy gap with the temperature of the $\mathrm{TiO}_{2}$ solids obtained from the three different Triton $\mathrm{X}$ gels and after calcination at various temperatures between $400{ }^{\circ} \mathrm{C}$ and $800^{\circ} \mathrm{C}(\mathrm{B})$.

and the water molecules. ${ }^{22,34}$ Taking into account that the concentration of the reactants is similar in all three systems, it could be expected that in the case of Triton X-100, the innerspace is the largest and hence it is expected that fewer particles with an increased crystallinity would be formed. This is generally in agreement with the experimental results. However,

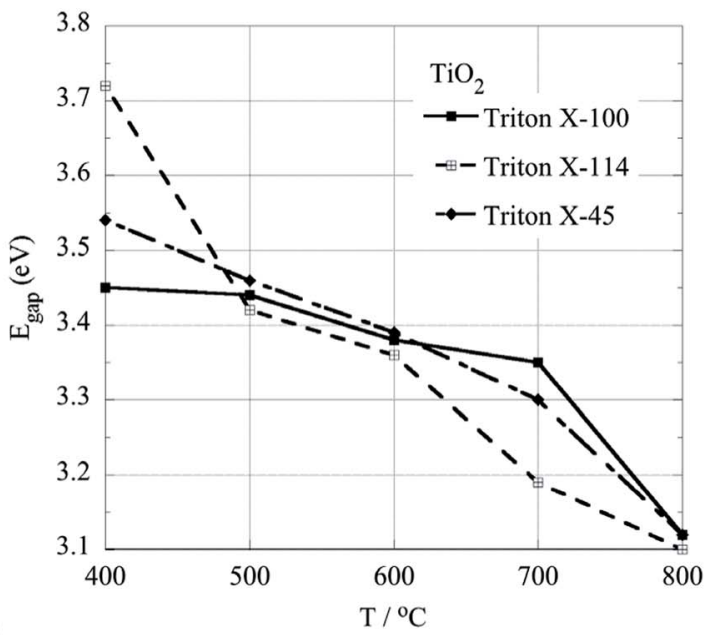

(B)

in the case of Triton X-114, the particles formed present the smallest size, most probably due to stronger interactions of this surfactant with the precursor molecules, which affect the morphology and crystallinity of the formed solids. ${ }^{6}$

The advantages of using non-ionic reverse micelles in the synthesis of nanoporous titania include the use of the droplets 
a)

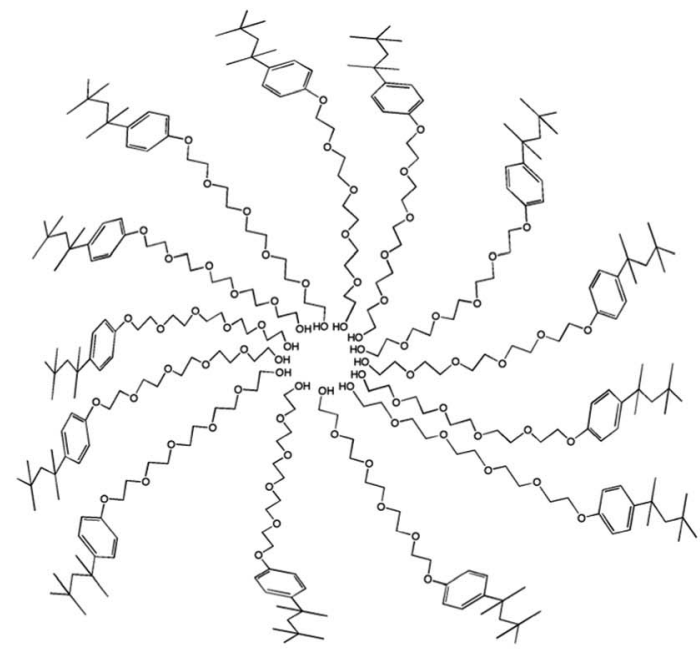

b)

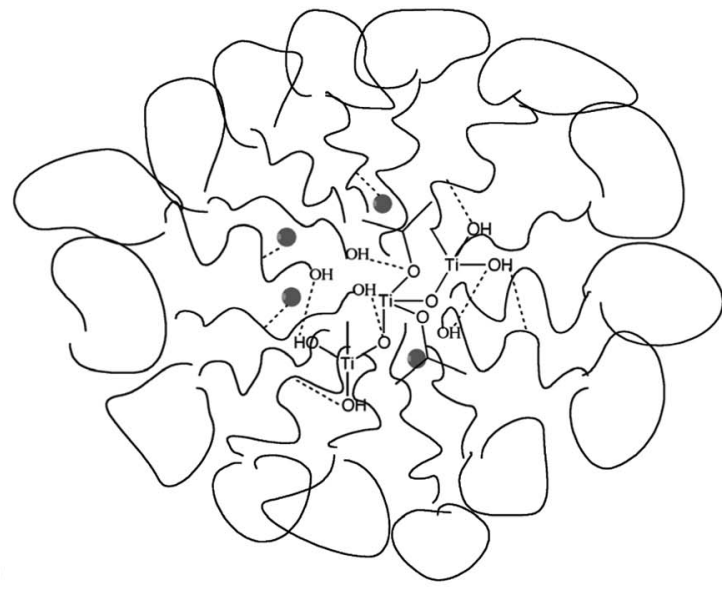

Fig. 10 Schematic illustration of (a) a reversed micelle formed by the Triton X-45 surfactant in a non-polar solvent and (b) the interactions between hydrolysed $\mathrm{Ti}\left(\mathrm{O}^{\mathrm{P} P r}\right)_{4}$ and the ethylenoxy groups of the polar surfactant tails.

Table 4 Comparison of the synthesis methods of porous titania

\begin{tabular}{|c|c|c|c|c|}
\hline Method & $\begin{array}{l}\text { Temperature } \\
\text { condition }\left({ }^{\circ} \mathrm{C}\right)\end{array}$ & $\begin{array}{l}\text { Surface area } \\
\left(\mathrm{m}^{2} \mathrm{~g}^{-1}\right)\end{array}$ & $\begin{array}{l}\text { Particle size } \\
(\mathrm{nm})\end{array}$ & References \\
\hline $\mathrm{TiO}_{2} \mathrm{TrX}-100$ сус & 400 & 182.2 & 6.31 & - \\
\hline $\mathrm{TiO}_{2} \mathrm{TrX}-45$ cyc & 400 & 146.3 & 6.3 & - \\
\hline $\begin{array}{l}\text { Cyclohexane/Triton X-114/ } \\
\text { water/Ti }\left(\mathrm{OC}_{3} \mathrm{H}_{7}\right)_{4}=11 / 1 / 1 / 1 \\
(\text { volume ratio TrX-114/ } \\
\text { cyclohexane }=0.49)\end{array}$ & 400 & 139 & 6.3 & Matějová et al., 2010 (ref. 55) \\
\hline $\begin{array}{l}\mathrm{TiO}_{2} \text { film } \mathrm{TiCl}_{4} / \text { Triton X-100/ } \\
\text { water }\end{array}$ & $\sim 400$ & 44.6 & 60 & Al-Omair et al., 2014 (ref. 56) \\
\hline $\begin{array}{l}\mathrm{RM}-\mathrm{TiO}_{2} \text { : cyclohexane/ } \\
\text { Triton X-114/water/ } \\
\mathrm{Ti}\left(\mathrm{OC}_{3} \mathrm{H}_{7}\right)_{4}=11 / 1 / 1 / 124 \mathrm{~h} \\
\text { gel }\end{array}$ & 400 & 48 & 12 & $\begin{array}{l}\text { Rajalakshmi et al., } 2012 \\
\text { (ref. 57) }\end{array}$ \\
\hline
\end{tabular}

as reaction vessels, the size of which can, to some extent, be regulated by the use of the surfactant employed. The use of reverse micelles provides a means of keeping apart the reagents for the synthesis of titanium oxide and for controlling the rate of reaction. Further, this helps control the properties of the porous product, and limits the extent of aggregation. Further, the use of sol medium for the synthesis leads to a homogeneous mixing of the titanium oxide precursors.

A comparison of different synthetic methods for the synthesis of mesoporous $\mathrm{TiO}_{2}$ materials is presented in Table 4 .

\section{Conclusions}

From the discussion above, we can reach the following conclusions. The use of different Triton-X surfactants with different tail lengths can significantly affect and accordingly adjust the surface properties of $\mathrm{TiO}_{2}$ solids. In general, it has been found that increasing the tail length results in larger titania particles with increased crystallinity and higher thermal stability. The matrix Triton- $X$ stabilizes the anatase structure by hindering the phase transformation from anatase to rutile, which is started at $T>700{ }^{\circ} \mathrm{C}$. In the case of a medial length of polar surfactant tail, i.e. in the case of Triton X-114, it rather seems that the certain length favours a better penetration and interaction with the precursors oligomers, resulting in the formation of solids with improved textural characteristics. The effects are corroborated by a large spectrum of porous solids characterisation methods, such as $\mathrm{N}_{2}$ adsorption, XRD, DRUV-Vis and FTIR. The Triton-X reverse microemulsions could be identified as ideal micro-reactors for the synthesis of solids with tuneable and defined porous and morphology. 


\section{Conflicts of interest}

There are no conflicts to declare.

\section{Acknowledgements}

We thank Professor Ioannis Giapintzakis and Dr Elli Symeou and Dr Ioanna Savva for providing access to SEM facilities and assistance with measurements (Department of Mechanical \& Manufacturing Engineering at University of Cyprus). Also, we thank Professor Ioannis Pashalidis for providing access to the UV-Vis absorption, ATR-FTIR and DRUV-Vis solid state facilities.

\section{References}

1 I. H. Chowdhury, P. Bose and M. K. Naskar, J. Alloys Compd., 2016, 668, 56-64.

2 S. Patra, C. Andriamiadamanana, M. Tulodziecki, C. Davoisne, P. L. Taberna and F. Sauvage, Sci. Rep., 2016, 6, 1-7.

3 N. M. Nursam, J. Z. Y. Tan, X. Wang, W. Li, F. Xia and R. A. Caruso, ChemistrySelect, 2016, 1, 4868-4878.

4 J. L. Vivero-Escoto, Y. D. Chiang, K. C. W. Wu and Y. Yamauchi, Sci. Technol. Adv. Mater., 2012, 13, 1-9.

5 X. Chen and S. S. Mao, Chem. Rev., 2007, 107, 2891-2959.

6 A. Zielinska-Jurek, J. Reszczynska, E. Grabowska and A. Zaleska, Microemulsions - An Introduction to Properties and Applications, ed. R. Najjar, Rijeka, InTech., 2012, pp. 229-250.

7 S. M. Gupta and M. Tripathi, Cent. Eur. J. Chem., 2012, 10, 279-294.

8 A. Pucci and N. Pinna, Z. Naturforsch. B Chem. Sci., 2010, 65, 1015-1023.

9 J. Yu, L. Zhang, B. Cheng and Y. Su, J. Phys. Chem. C, 2007, 111, 10582-10589.

10 J. Akilavasan, K. Wijeratne, H. Moutinho, M. Al-Jassim, A. R. M. Alamoud, R. M. G. Rajapakse and J. Bandara, J. Mater. Chem. A, 2013, 1, 5377-5385.

11 W. N. Wang, I. W. Lenggoro, Y. Terashi, T. O. Kim and K. Okuyama, Mater. Sci. Eng., B, 2005, 123, 194-202.

12 S. Chin, E. Park, M. Kim and J. Jurng, Powder Technol., 2010, 201, 171-176.

13 H. E. Namin, H. Hashemipour and M. Ranjbar, Int. J. Mod. Phys. B, 2008, 22, 3210-3215.

14 H. S. Hafez, Mater. Lett., 2009, 63, 1471-1474.

15 C. Youping, S. Hongqi, J. Wanqin and X. Nanping, Chin. J. Chem. Eng., 2007, 15, 178-183.

16 S. Yin, Q. Zhang, F. Saito and T. Sato, Chem. Lett., 2003, 32, 358-359.

17 S. Rani, S. C. Roy, M. Paulose, O. K. Varghese, G. K. Mor, S. Kim, S. Yoriya, T. J. LaTempa and C. A. Grimes, Phys. Chem. Chem. Phys., 2010, 12, 2780-2800.

18 S. Masson, P. Holliman, M. Kalaji and P. Kluson, J. Mater. Chem., 2009, 19, 3517-3522.

19 L. Shi, C. Li, A. Chen, Y. Zhu and D. Fang, Mater. Chem. Phys., 2000, 66, 51-57.
20 X. Wu, Q. Z. Jiang, Z. F. Ma, M. Fu and W. F. Shangguan, Solid State Commun., 2005, 136, 513-517.

21 K. Yang, J. Zhu, J. Zhu, S. Huang, X. Zhu and G. Ma, Mater. Lett., 2003, 57, 4639-4642.

22 B. K. Paul and S. P. Moulik, Curr. Sci., 2001, 80, 990-1001.

23 A. Bumajdad, J. Eastoe and A. Mathew, Adv. Colloid Interface Sci., 2009, 147-148, 56-66.

24 J. Eastoe, M. J. Hollamby and L. Hudson, Adv. Colloid Interface Sci., 2006, 128-130, 5-15.

25 N. Pal and A. Bhaumik, Adv. Colloid Interface Sci., 2013, 189, 21-41.

26 L. H. Lee and W. C. Chen, Chem. Mater., 2001, 13, 1137-1142.

27 M. A. Malik, M. Y. Wani and M. A. Hashim, Arabian J. Chem., 2012, 5, 397-417.

28 S. N. Khadzhiev, K. M. Kadiev, G. P. Yampolskaya and M. K. Kadieva, Adv. Colloid Interface Sci., 2013, 197-198, 132-145.

29 P. T. Tanev and T. J. Pinnavaia, Science, 1995, 267, 865-867. 30 S. Jaiswal, R. Mondal, D. Paul and S. Mukherjee, Chem. Phys. Lett., 2016, 646, 18-24.

31 M. Johnson, Mater. Methods, 2016, 3, 163.

32 O. Šolcová, L. Matějová, P. Klusoň, Z. Matěj, Z. Strýhal, J. Pavlík and T. Cajthaml, Sol-Gel Methods for Materials ProcessingSpringer Netherlands, 2008, pp. 441-446.

33 L. Matějová, Z. Matěj, R. Fajgar, T. Cajthaml and O. Šolcová, Mater. Res. Bull., 2012, 47, 3573-3579.

34 E. Stathatos, P. Lianos, F. D. Monte, D. Levy and D. Tsiourvas, Langmuir, 1997, 13, 4295-4300.

35 R. Inaba, T. Fukahori, M. Hamamoto and T. Ohno, J. Mol. Catal. A: Chem., 2006, 260, 247-254.

36 S. Mahshid, M. S. Ghamsari, M. Askari, N. Afshar and S. Lahuti, Semicond. Phys., Quantum Electron. Optoelectron., 2006, 9, 65-68.

37 N. Uekawa, N. Endo, K. Ishii, T. Kojima and K. Kakegawa, J. Nanotechnol., 2012, 2012, 1-8.

38 P. Kluson, P. Kacer, T. Cajthaml and M. Kalaji, Chem. Biochem. Eng., 2003, 17, 183-190.

39 A. L. Castro, M. R. Nunes, A. P. Carvalho, F. M. Costa and M. H. Florêncio, Solid State Sci., 2008, 10, 602-606.

40 M. V. Swapna and K. R. Haridas, Chemist, 2015, 88, 1-6.

41 J. Dharma and A. Pisal, Perkin Elmer Application Notes, United Kingdom, 2009.

42 S. Bagheri, K. Shameli and S. B. A. Hamid, Journal of Chemistry, 2012, 2013, 1-5.

43 D. Zhu and Z. A. Schelly, Langmuir, 1992, 8, 48-50.

44 C. R. Theocharis, Multifunctional Mesoporous Inorganic Solids, Kluwer Academic Publishers, 1993, vol. 400, pp. 3-18.

45 K. S. W. Sing, Colloids Surf., A, 2001, 187-188, 3-9.

46 E. P. Barrett, L. G. Joyner and P. P. Halenda, J. Am. Chem. Soc., 1951, 73, 373-380.

47 N. A. Al-Omair, S. M. Reda and F. M. Al-Hajri, Adv. Mater. Phys. Chem., 2014, 4, 29-32.

48 A. A. Belhekar, S. V. Awate and R. Anand, Catal. Commun., 2002, 3, 453-458.

49 F. A. Deorsola and D. Vallauri, Powder Technol., 2009, 190, 304-309. 
50 T. Anukunprasert, C. Saiwan, E. D. Bartolomeo and E. Traversa, J. Electroceram., 2007, 18, 295-303.

51 V. H. Castrejón-Sánchez, E. Camps and M. Camacho-López, Superficies Vacio, 2014, 27, 88-92.

52 M. Andersson, L. Österlund, S. Ljungström and A. Palmqvist, J. Phys. Chem. B, 2002, 106, 10674-10679.

53 P. Kluson, P. Kacer, T. Cajthaml and M. Kalaji, J. Mater. Chem., 2001, 11, 644-651.

54 M. E. Simonsen and E. G. Søgaard, J. Sol-Gel Sci. Technol., 2010, 53, 485-497.
55 L. Matějová, T. Cajthaml, Z. Matěj, O. Benada, P. Klusoň and O. Šolcová, J. Supercrit. Fluids, 2010, 52, 215-221.

56 N. A. Al-Omair, S. M. Reda and F. M. Al-Hajri, Adv. Mater. Phys. Chem., 2014, 4, 29-32.

57 K. Rajalakshmi, V. Jeyalakshmi, K. R. Krishnamurthy and B. Viswanathan, Indian J. Chem., Sect. A: Inorg., Bio-inorg., Phys., Theor. Anal. Chem., 2012, 51, 411-419.

58 K. Kočí, L. Obalová, L. Matějová, D. Plachá, Z. Lacný, J. Jirkovský and O. Šolcová, Appl. Catal., B, 2009, 89, 494-502. 